\title{
PUSH-OUT BOND STRENGTH OF DIFFERENT ESTHETIC POSTS AN IN VITRO STUDY
}

\begin{abstract}
Ahmed Hamdy*
ABSTRACT

PURPOSE: This in vitro study measured push-out bond strength of different posts as function of radicular regions.

Statement of problem: In non circular or excessively flared root canals,prefabricated posts may not fit well,increasing cement thickness and bubbles at coronal level which may alter its mechanical performance causing impaired post retention.

Methods:40 sound extracted human central incisors were used in this study. All teeth were endodontically treated and decoronated $2 \mathrm{~mm}$ above CEJ. Then were randomly divided into 4 groups of 10 each regarding type of post used:group 1(PD): Polymer infiltrated ceramic,Paradigm MZ 100(3M-ESPE); group 2(FRC)Fiber post,Postec Plus (Ivoclar Vivadent); group 3 (ZR): Lava Zirconium dioxide blocks(3M-ESPE); group 4(CP):Cosmo Post, Zirconium dioxide (Ivoclar Vivadent). All posts were luted with Panavia 21(Kuraray Noritake, Japan). Push-out tests were performed to evaluate the bond strength of different posts at different radicular regions.Data were statistically analyzed using one way (ANOVA)and Scheffe test made pairwise comparison $(\alpha=0.05)$.

Results: FRC group recorded the highest bond strength (11.78 $\pm 0.79 \mathrm{MPa})$. PD group showed higher results $(10.10 \pm 1.12 \mathrm{MPa})$ than $\mathrm{ZR}(9.56 \pm 0.85 \mathrm{MPa})$ and $\mathrm{CP}(7.93 \pm 0.89 \mathrm{MPa})$ and the 2 latter groups were not significantly different from each other $\mathrm{p} \leq 0.05$.Regardless to post type, it was found that middle region recorded highest bond strength means value, then apical region meanwhile the lowest bond strength values were recorded at cervical regions $\mathrm{p} \leq 0.05$.

Conclusions: 1- Push-out bond strength of different esthetic posts are significantly affected by the type of its materials and manufacturing; FRC recorded the highest bond strength values,PD recorded intermediate values, ZR and $\mathrm{CP}$ showed the least values with no significant difference between them.(P $\leq 0.05)$ 2-Regardless to type of post , the middle radicular region recorded the highest bond strength then apical region, meanwhile cervical region showed the lowest bond strength values $\mathrm{P} \leq 0.05$.
\end{abstract}

* Assistant professor,Fixed Prosthodontics Department,Faculty of Dentistry,October University for Modern Sciences and Arts. 


\section{INTRODUCTION}

Partially yttrium-stabilized zirconium-oxide post systems were introduced in mid 1990s by various researchers ${ }^{(1,2)}$.Pure zirconia material shows polymorphic phase transformation from a cubic, to tetragonal, to monoclinic phase, accompanied by a high volume change when cooling down after sintering, which makes the sintered body unstable. Therefore, dental zirconia material contains 3 to 6 wt \% Y203 as an additive to stabilize the ceramic in the tetragonal phase that is usually not stable at room temperature ${ }^{(3)}$ Zirconium-oxide posts demonstrate high fracture resistance due to high flexural strengths, which is comparable to that of cast gold posts and cores or titanium posts ${ }^{(4,5)}$. Fractures of teeth restored with zirconium-oxide posts are often unrestorable,whereas in vitro studies on fracture strengths of FRC posts showed less catastrophic failures due to a modulus of elasticity that is closer to that of dentin ${ }^{(6)}$.

Different resin luting agents and corresponding bonding systems have been proposed for cementing tooth-colored posts and can be generally divided into conventional bis-GMA-based resin luting agents and so-called adhesive resin luting agents containing functional monomers such as 10-Methacryloyloxydecyl hydrogen phosphate (10-MDP) or 4-methacryloxyethyl trimellitate anhydride (4-META) $)^{(7)}$. Several in vitro studies reported controversial results regarding bond strengths of different luting agents to endodontic posts and root canal dentin ${ }^{(8)}$.

Bonding to zirconium-oxide ceramics requires different pretreatment procedures compared to glass ceramics $^{(9)}$.

High-strength zirconium-oxide ceramics are not silica based; therefore, chemical silica-silane bonds cannot be established ${ }^{(10)}$. Moreover, the application of acidic agents such as phosphoric or hydrofluoric acid to zirconium-oxide ceramic will not create a sufficiently roughened surface for enhanced micromechanical retention ${ }^{(11)}$. Thus, various pretreatment procedures have been recommended. Airborne-particle abrasion with alumina particles changes the structure of the surface by plastic deformation and roughening, resulting in an increased surface area and a volume loss of material ${ }^{(12)}$.

There are many structural differences between radicular and coronal dentin ,as well as problems related to presence of endodontic sealers,provisional cements and irrigant solutions violating the bond between post and radicular dentin ${ }^{(13)}$. When mismatch exist between post size and post space diameter,the resin cement layer would be excessively thick and bubbles are likely to form in it,thus predisposing to bonding failure ${ }^{(14)}$.

For large, non circular or tapered canal ,post systems that rely on use of a cylindrical prefabricated post may not achieve the intimate adaptability of the post to the canal, possibly compromising the retention of the post ${ }^{(15)}$. When these factors are assessed, a custom made milled posts and cores would be an alternative treatment option in some clinical cases. Butz et al ${ }^{(15)}$ reported that survival rates and fracture strengths of prefabricated zirconia posts with composite cores are significantly lower, so this combination are not recommended for clinical use.

Dentin is a heterogeneous material. Its characteristics vary widely among individuals, even within the same individual. Age plays a decisive role because dentin undergoes age-associated changes. Young dentin has wide, open tubules. With increasing age, the number of tubules decreases and tubular diameter becomes narrower as a result of sclerotic processes and the deposition of secondary and tertiary dentin ${ }^{(16)}$.This process results in reduced bond strength because the penetration of resin into and around the dentinal tubules is responsible for nearly $40 \%$ of the bond strength ${ }^{(17)}$ There is no in vitro or in vivo evidence of the long-term stability 
of dentin bonding procedures ${ }^{(16)}$ It has been reported that bond strength decreases over time under the influence of water, temperature changes, and dynamic loading ${ }^{(18)}$.

Dietschi et $\mathrm{al}^{(19)}$ conducted an in vitro fatigue test and reported that the interface between adhesive posts and dentin exhibited substantial defects after intermittent loading and thermal cycling. Also, poor bonding of composite resin to the zirconia post was reported. In addition to problems of bonding to dentin in general, there are difficulties associated with the use of adhesive systems in root canals. There are structural differences between radicular dentin and coronal dentin as well as problems related to the presence of provisional cements,endodontic sealers, and rinsing solutions in a canal with limited access $^{(13-20)}$ Radicular dentin can be divided into apical, middle, and coronal thirds ${ }^{(21)}$. In the middle and coronal thirds, significantly lower values for the bonding strength have been measured ${ }^{(22)}$ Conventional cements offer advantages over resin cements, including lower costs and less complicated procedures with less opportunities for procedural $\operatorname{error}^{(23,24)}$.

Different resin luting agents and corresponding bonding systems have been proposed for cementing tooth-colored posts and can be generally divided into conventional bis-GMA-based resin luting agents and so-called adhesive resin luting agents containing functional monomers such as 10-Methacryloyloxydecyl hydrogen phosphate (10MDP) or 4-methacryloxyethyl trimellitate anhydride (4-META) ${ }^{(25)}$ Several in vitro studies reported controversial results regarding bond strengths of different luting agents to endodontic posts and root canal dentin ${ }^{(25,26)}$. The null hypothesis of this study was set for two variables:1-No difference in bond strength values between different types of posts.2Different radicular regions have the same bond strength to different posts.

\section{MATERIALS AND METHODS}

- A total of forty sound freshly extracted upper central incisors were selected after proper inspection to ensure the absence of any defects. All teeth were decoronated $2 \mathrm{~mm}$ above cemento-enamel junction and prepared using rotary files (ProTaper, Dentsply, Switzerland).

- The canals were enlarged to size F4 file,irrigated with $2.5 \%$ sodium hypochlorite solution and obturated using F4 tapered single cone with eugenol-free resin sealer(AH26,Dentsply).

- Methyl methacrylate cylinders were fabricated for this study and received $18 \mathrm{~mm}$ deep standardized drill holes with a diameter of $3.5 \mathrm{~mm}$. The holes were filled with self cure methyl methacrylate (Technovit 4071; Heraeus Kulzer ,Hanau,Germany).

- Subsequently ,post space preparations with a length of $13 \mathrm{~mm}$ were prepared with dedicated drill provided by the post manufacturer (Reamer 1.7mm \#572712; Ivoclar Vivadent) (Fig.1).

\section{Types of posts:}

Zirconium oxide posts (CosmoPost; Ivoclar Vivadent, Schaan, Liechtenstein) - Glass-fiber-reinforced composite posts (FRC Postec; Ivoclar vivadent) (coronal diameter 2.0mm; size 3) FRC posts contain unidirectional silane-coated glass fibers (61.5\% weight), which are embedded in a polymer matrix of triethylene-glycol-dimethacrylates (TEGMA) and urethane -dimethacrylates (UDMA)in combination with highly dispersed silicone dioxide.

Polymer infiltrated ceramic, 3M Paradigm MZ100 Block Cerec (Sirona, Germany) contains $85 \%$ ultrafine zirconia-silica ceramic particles that reinforce a highly cross linked polymeric matrix.The polymer matrix consists of bisGMA (Bisphenol A diglycidyl ether dimethacrylate) and TEGDMA(triethylene glycol dimethacrylate), and employs a patented ternary initiator system. 
Zirconium dioxide blocks-Dentsply (Sirona, Germany).

According to previous studies ${ }^{(27,28)}$, impression of post and core spaces were taken with $\mathrm{C}$ type light and heavy viscosity silicone based impression material (Zeta Plus; Zhermack, Badia Polesine,Italy) mixed and applied inside root canals .

After taking the impressions, dies were prepared and scanned by laser in laboratory for acquiring and transmitting informations. Full Digital impressions were made with an extra-oral scanner (inEos X5; Sirona, Germany) to generate virtual models. Special software (in Lab SW 4.2.1.61068, Sirona Dental Systems, Bensheim, Germany) was used to design the post and core restorations.

All samples were luted with Panavia 21 (Kuraray Noritake Dental Inc. Japan) resin cement following manufacturer instructions and stored in distilled water at $37^{\circ} \mathrm{C}$ for 24 hours before testing.

Thermocycling was done for all samples, 5000 cycles $\left(5-55^{\circ} \mathrm{C}\right)$ every 30 seconds.

Samples were sectioned horizontally perpendicular to their long axis with a slow speed diamond blade (Isomet 1000, Buehler Ltd.) under water cooling .Three horizontal sections $(2 \pm 0.1 \mathrm{~mm})$ thick were obtained from coronal,middle and apical regions of each root.Every root slice was secured in a custom made loading fixture.

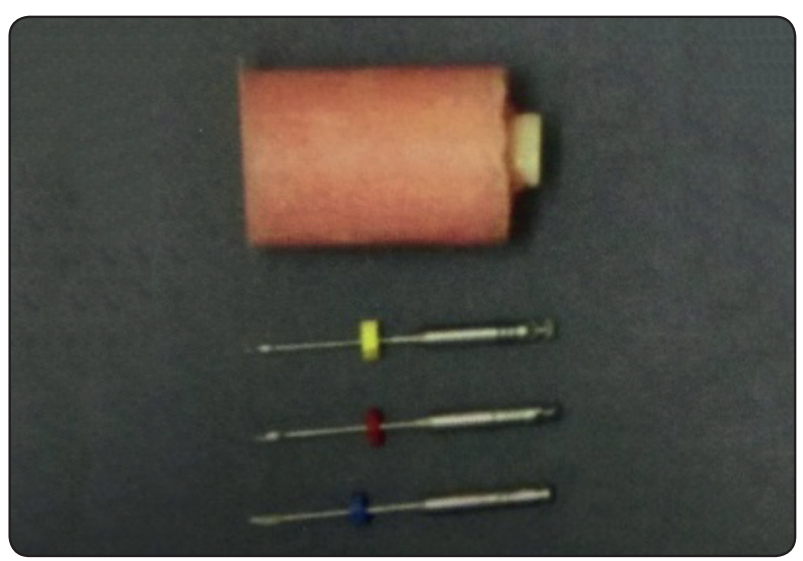

Fig. (1) Reamers for post space preparation
Each sample was mounted in custom made loading fixture (Fig.2) and subjected to compressive loading via computer controlled testing machine and loaded at crosshead speed of $0.5 \mathrm{~mm} / \mathrm{min}$.The load applied by plungers size of $(1,0.75$ and $0.5 \mathrm{~mm})$ in an apical coronal direction because of the convergence of the root canal sections.Selected diameter of the plunger was positioned so it only contacts the filling to displace it down ward.This guaranteed that root dentine was sufficiently supported during loading process.(Fig. 2)

-Maximum failure load was recorded in $\mathrm{N}$ and converted into MPa.Bond strength was calculated from the recorded peak load divided by surface area as follows:Bond=F/A $\mathrm{A}=\pi \mathrm{h}(\mathrm{r} 1+\mathrm{r} 2)$

Where $\pi$ is the constant $3.14, \mathrm{r} 1$ is apical radius, $\mathrm{r} 2$ coronal one, and $\mathrm{h}$ is the thickness of sample in millimeters.

Failure was manifested by extrusion of filling material and confirmed by sudden drop along loaddeflection curve recorded by computer software (Nexygen ; Lloyd Instruments Ltd).All data were collected, tabulated and statistically analyzed.

SPSS version 23.0 was used for data management. Mean and standard deviation described push out bond strength. One way ANOVA made comparisons between groups and Scheffee test made pairwise comparisons. Pvalue alwa ys 2 tailed and significant at 0.05 level.

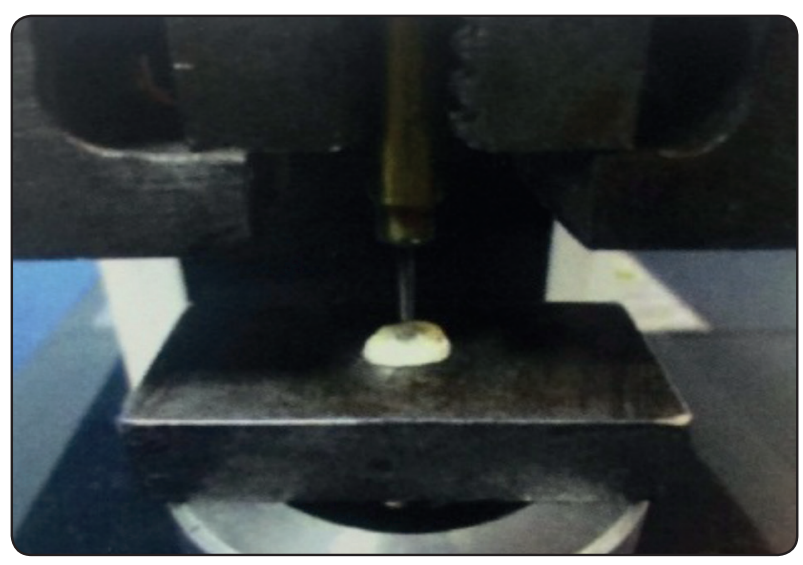

Fig. (2) Push-out test 


\section{RESULTS}

Descriptive statistics of push-out bond strength results measured (MPa)of four types of posts in three different radicular regions as presented in table (1) and Fig.(3).It was found that FRC posts recorded the highest bond strength than $\mathrm{PD} . \mathrm{ZR}$ and $\mathrm{CP}$ showed the least results with no significant difference .

Regarding bond strength to radicular regions; the middle recorded higher results than apical.Cervical showed the least bond strength values as shown in Graph .1

TABLE (1) Comparison of push-out bond strength as mean \pm standard deviation for different post as a function of radicular region

\begin{tabular}{|c|c|c|c|c|c|}
\hline \multirow[b]{2}{*}{ Radicular region } & \multicolumn{4}{|c|}{ Study groups } & \multirow[b]{2}{*}{ P value } \\
\hline & PD & FRC & $\mathbf{Z R}$ & $\mathbf{C P}$ & \\
\hline Cervical & $8.77 \pm 0.73 \mathbf{b}$ & $10.15 \pm 1.19 \mathbf{a}$ & $7.12 \pm 0.72 \mathbf{c}$ & $7.01 \pm 0.61 \mathbf{c}$ & $<0.001$ \\
\hline Middle & $10.10 \pm 1.12 \mathbf{b}$ & $11.78 \pm 0.79 \mathbf{a}$ & $9.56 \pm 0.85 \mathbf{b}$ & $7.93 \pm 0.89 \mathbf{c}$ & $<0.001$ \\
\hline Apical & $9.76 \pm 1.22 \mathbf{a}$ & $10.52 \pm 0.88 \mathbf{a}$ & $7.56 \pm 0.66 \mathbf{c}$ & $7.31 \pm 0.81 \mathbf{c}$ & $<0.001$ \\
\hline
\end{tabular}

P value is significant £0.05. Groups sharing same letter within same raw (or region) are not significantly different.

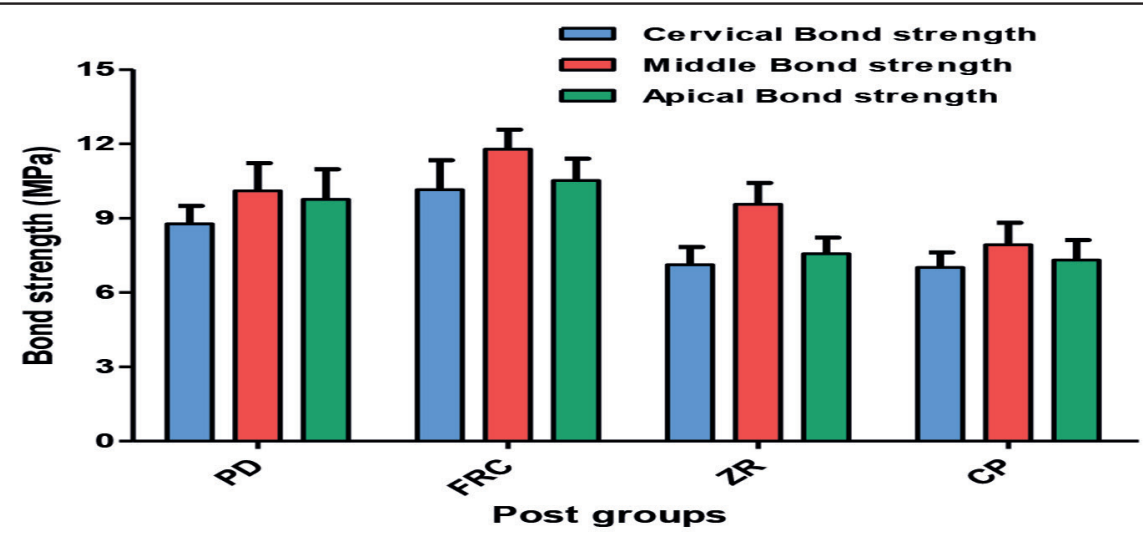

Fig. (3) Push-out bond strength (MPa) as mean values for different posts as a function of radicular region

\section{DISCUSSION}

Results of this in vitro study,support rejection of null hypothesis of this study ,push-out bond strength were significantly affected by different types of posts and different radicular regions showed different bond strength values.
Superior results of fiber posts can be explained in the light of adhesion and chemical bonding between composite and the fiber post that are essentially composite materials composed of fibers of silica surrounded by a matrix of polymer resin.,this results agreed with others. ${ }^{(29,46,48)}$ 
The push-out test was utilized for bond strength testing in $75 \%$ of literatures published from 2007 to 2016 as it provides a practical tool for assessment the interfacial shear strength between post and root canal walls as has the benefit of more simulating the clinical condition ${ }^{(30)}$. The push-out test is easy to perform and has less cohesive failures in pretest and small standard deviations ${ }^{(31)}$. Push-out tests also showed more homogenous stress distribution by finite element stress analysis. The push out test is an indicative to retention of fiber post in root canal as it mimics the forces that act on the post in apicocoronal direction $^{(31)}$.

The Low results of Cosmo-Posts in this study, may be explained due to increase thickness of resin cement than in custom made that may involve bubbles,voids and other defects and act as crack centers and decrease post retention. ${ }^{(32)}$

Regarding results at different radicular regions; the middle third showed the highest then apical and cervical showed the lowest results, this agreed with Mannocci et al.2003( ${ }^{33)}$ who reported that middle and apical radicular dentin showed the lower densities of dentinal tubules and found to be more resistant to tension than the coronal third.

Malyk et al.2010 ${ }^{(34)}$ stated that intraradicular dentin in the coronal level presents a larger number of tubules and therefore less intertubular dentin, which is usually associated with higher bond strength as reported by Giannini et al 2001(35) and Bitter et al $2009^{(36)}$ who stated that the bond to root dentine is related inversely with tubules diameters and related directly to the percentage of solid dentine.i.e intertubular dentin and the increase in the number of resin tags is not directly proportional to the bond strength,.Daleprane et al.2016 ${ }^{(37)}$ defended this hypothesis that although the dentin in the apical third may be more likely to present residues of endodontic treatment ${ }^{(38)}$, the bond strength appears to be enhanced by the technical sensitivity of the luting system. The lower volume of cement at apical level may have reduced the polymerization shrinkage stress, thus increasing bond strength values of all resin cements to root dentin ${ }^{(39)}$.

Results of bonding at apical third were less than middle third in different groups as apical region is devoid tubules, presence of irregular secondary dentin,cementum like tissue on the root canal wall and numerous accessory canals ${ }^{(35)}$.Also,the decrease in degree of resin cements conversion in deepest areas of the cavity due to inaccessibility of curing irradiation ${ }^{(40)}$. Even with dual cured material, deeper portions of cement are inaccessible to light, rendering the material dependent on chemical curing.This can reduce the degree of conversion of the cement and consequently affect its mechanical properties $^{(41)}$.

Moreover, it has been reported that the root canal dentin walls after post space preparation are covered with remnnants of gutta -percha and sealer, rough debris and a thick smear removed ${ }^{(42)}$; thus may limit the adhesion.

On the contrary to the previous hypothesis, Gaston et al 2001.(43) Bitter et al 2006 ${ }^{(44)}$ and Daleprane et al $2016^{(37)}$ reported significant higher bond strength at the apical third.

Induced micro-roughness from milling tools to Zirconium dioxide blocks enhanced higher bond strength between posts and resin cement and this may explain the higher bond strength achieved in this group compared to smooth Cosmo-post zirconium dioxide ${ }^{(45)}$.

In case of retreatment, fiber posts are easily removed by a drill, while ceramic posts,even using a diamond bur, Mhardly can be removed ${ }^{46)}$, they are very stiff with no plastic behavior ${ }^{(47)}$. Stiffness of ceramic posts can be less favorable clinically than fiber posts in respect to risk of root fracture. In fact a number of in vitro studies demonstrated that fracture type is more benign with fiber posts than when ceramic posts were used. ${ }^{(48)}$

Cementation technique also has an important effect upon eventual retention and stress distribution 
of the post ${ }^{(49)}$. According to several studies ${ }^{(50,51)}$, the introduction of cement into the root canal is essential to achieve a uniform bubble -free layer of cement that distributes stresses evenly through the entire root canal.

Of all the methods investigated ${ }^{(52,53)}$, the use of lentulospiral to place cement in the canal is superior, as it gives better spinning and spreading of cement because of centrifugal dispersion of cement. This method also reduces voids and increases the contact of cement with the walls.

During cementation ,the post space should be free of any residue, as it has been reported that even a small nodule on the post surface or temporary cement residue in the canal can generate enough force to cause root fracture during and after post cementation. $^{(90)}$

\section{CONCLUSIONS}

1. Push-out bond strength of different esthetic posts are significantly affected by the type of its materials and manufacturing.

2. FRC recorded the highest bond strength value, $\mathrm{PD}$ recorded intermediate value, $\mathrm{ZR}$ and $\mathrm{CP}$ showed the least values with no significant difference between them. $(\mathrm{P} \leq 0.05)$

\section{Clinical Implications}

Fiber reinforced composite posts showed significantly higher in-vitro bond strength values than zirconium-oxide posts .Therefore,FRC posts may be suitable to resist the loss of retention of endodontic posts.

\section{REFERENCES}

1. Meyenberg KH, Luthy H, Schaerer P. Zirconia posts: a new all-ceramic concept for nonvital abutment teeth. J Esthet Dent 1995;7:73-80.

2. Dietschi D, Romelli M, Goretti A. Adaptation of adhesive posts and cores to dentin after fatigue testing. Int J Prosthodont 1997;10:498-507.
3. Piconi C, Maccauro G. Zirconia as a ceramic biomaterial. Biomaterials 1999;20:1-25.

4. Pontius O, Hutter JW. Survival rate and fracture strength of incisors restored with different post and core systems and endodontically treated incisors without coronoradicular reinforcement. J Endod 2002;28:710-5.

5. Heydecke G, Butz F, Strub JR. Fracture strength and survival rate of endodontically treated maxillary incisors with approximal cavities after restoration with different post and core systems: an in-vitro study. J Dent 2001;29:427-33

6. Akkayan B, Gulmez T. Resistance to fracture of endodontically treated teeth restored with different post systems. J Prosthet Dent 2002;87:431-7.

7. Sahafi A, Peutzfeld A, Asmussen E, Gotfredsen K. Effect of surface treatment of prefabricated posts on bonding of resin cement. Oper Dent 2004;29:60-8.

8. Mendoza DB, Eakle WS. Retention of posts cemented with various dentinal bonding cements. J Prosthet Dent 1994;72:591-4.

9. Ozcan M, Vallittu PK. Effect of surface conditioning methods on the bond strength of luting cements to ceramic. Dent Mater 2003;19:725-31.

10. Blatz MB, Sadan A, Kern M. Resin-ceramic bonding: a review of the literature. J Prosthet Dent 2003;89:268-74.

11. Awliya W, Oden A, Yaman P, Dennison JB, Razzoog ME. Shear bond strength of a resin cement to densely sintered high-purity alumina with various surface conditions. Acta Odontol Scand 1998;56:9-13.

12. Kern M, Thompson VP. Effects of sandblasting and silica-coating procedures on pure titanium. J Dent 1994; 22:300-6.

13. Nikaido T, Takano Y, Sasafuchi Y, Burrow MF, Tagami J. Bond strengths to endodontically treated teeth. Am J Dent 1999; $12: 177-80$

14. Anderson, D.J.:Measurement of stress in mastication. J. Dent. Res., 35:664-71, 1956.

15. Butz, F.; Lennon, A.M.; Heydecke, G. and Strub, J.R.: Survival rate and fracture strength of endodontically treated maxillary incisors with moderate defects restored with different post and core systems: An in vitro study. Int. J. Prosthodont., 14:58-64, 2001. 
16. Pospiech P. All-ceramic crowns: bonding or cementing? Clin Oral Invest 2002;6:189-97.

17. Yoshiyama M, Sano H, Ebisu S, Tagami J, Ciucchi B, Carvalno RM, et al. Regional strengths of bonding agents to cervical sclerotic root dentin. J Dent Res 1996; 75:1404-13.

18. Frankenberger R, Kramer N, Petschelt A. Fatigue behaviour of different dentin adhesives. Clin Oral Invest 1999;3:11-7.

19. Dietschi D, Romelli M, Goretti A. Adaptation of adhesive posts and cores to dentin after fatigue testing. Int $\mathrm{J}$ Prosthodont 1997; 10:498-507.

20. Sung EC, Tai ET, Chen T, Caputo AA. Effect of irrigation solutions on dentin bonding agents and restorative shear bond strength. J Prosthet Dent 2002;87:628-32.

21. Ferrari M, Mannocci F, Vichi A, Cagidiaco MC, Mjor IA. Bonding to root canal: structural characteristics of the substrate. Am J Dent 2000;13: 255-60

22. Yoshiyama M, Carvalho RM, Sano H, Horner JA, Brewer PD, Pashley DH. Regional bond strength of resins to human root dentine. J Dent 1996;24: 435-42.

23. Morgano SM, Brackett SE. Foundation restorations in fixed prosthodontics: current knowledge and future needs. J Prosthet Dent 1999;82: 643-57.

24. de la Macorra JC, Pradies G. Conventional and adhesive luting cements. Clin Oral Investig 2002;6:198-204.

25. Sahafi A, Peutzfeld A, Asmussen E, Gotfredsen K. Effect of surface treatment of prefabricated posts on bonding of resin cement. Oper Dent 2004;29:60-8.

26. Mendoza DB, Eakle WS. Retention of posts cemented with various dentinal bonding cements. J Prosthet Dent 1994;72:591-4.

27. Bittner N,Hill T, Randi A. Evaluation of a one-piece milled zirconia post and core with different post-and-core systems: An in vitro study. J Prosthet Dent.2010;103(6):369-379.

28. Yenisey, M., Kulunk, S .Effects of chemical surface treatments of quartz and glass fiber posts on the retention of a composite resin.J of Prosthet Dent.2008;99(1):38-45.

29. Artopoulou I,O`Keefe,K L and Powers J M.Effect of core diameter and surface treatment on the retention of resin composite cores to prefabricated endodontic posts.J of Prosthodont.2006;15(3):172-179.
30. Dos Santos F C,Banea M D,Carlo H L and De Barros S.Test methods for bond strength of glass fiber posts to dentin:A review,J of Adhesion.2016;20(4):231-234.

31. Goracci C,Tavares A,Fabianelli A,Monticelli F,Raffaelli O,Cardoso P C and Ferrrari M.The adhesion between fiber posts and root canal walls:Comparison between microtensile and push-out bond strength measurements .European Journal of Oral Sciences.2004;112(4):353-361.

32. Grandini S,Goracci C,Monticelli F,Borracchini A and Ferrari M.SEM evaluation of the cement layer thickness after luting two different posts.Journal of Adhesive Dentistry.2005;7(3):235-240.

33. Mannoci F,Pilecki P,Bertelli E and Watson T F.Density of dentinal tubules effect on tensile strength of root dentin. Dental Materials.2004;20(3):293-296.

34. Malyk Y,Kaaden C,Hickel and Illie N.Analysis of resin tags formation in root canal dentine:A cross sectional study.International Endodontic Journal.2010;43(1):47-56.

35. Giannini M,Carvalho R M,Martins L R,Dias C T and Pashley D H.The influence of tubule density and area of solid dentin on bond strength of two adhesive systems to dentin.Journal of Adhesive Dentistry.2001;3(4):315-324.

36. Bitter K,Paris S,Pfuertner C,Neumann K and Kielbassa A M.Morphological and bond strength evaluation of different resin cements to root dentin.European Journal of Oral Sciences.2009;117(3):326-333.

37. Daleprane B,Pereira C,Bueno A,Ferreira R,Moreira A and Magalhes C.Bond strength of fiber posts to root canal:Effects of anatomic root levels and resin cements. Journal of Prosthetic dentistry.2016;116(3):416-424.

38. Mjor I,Smith M,Ferrari,M and Mannoci F.The structure of dentine in the apical region of human teeth.International Endodontic Journal.2001;34(5):346-353.

39. Bouillaguet S, Troesch S, Wataha J, Krejci I, Meyer $\mathrm{J}$ and Pashley D.Microtensile bond strength between adhesive cements and root canal dentin.Dental Materials. 2003;19(3):199-205.

40. De Sousa Menezes M,Queiroz E,Soares P,Faria E Silva, Soares $\mathrm{C}$ and Martins L.Fiber post etching with hydrogen peroxide :Effect of concentration and application time. Journal of Endodontics.2011;37(3):398-402.

41. Faria A L,Reis A,Semec Para S,Roberto L and Martins M.The effect of luting techniques on the push-out bond strength of fiber posts. Braz J Oral Sci.2008;7(27):1653-1656. 
42. Bitter K, Noetzel J,Neumann K and Kielbassa A.Effect of silanization on bond strengths of fiber posts to various resin cements.Quintessence International .2007;38(2):121-128.

43. Gaston B,West L,Liewehr F, Fernandes C and Pashley D.Evaluation of regional bond strength of resin cement to endodontic surfaces.Journal of Endodontia.2001;27:321-324.

44. Bitter K,Meyer Lueckel H,Priehn K,Kanjuparambil J,Neumann K,and Kielbassa A.Effects of luting agent and thermocycling on bond strengths to root canal dentine. International Endodontic Journal.2006;39(10):809-818.

45. Ottl P., Hahn L., Ch H., Laver, H.Ch. and Fay, M.:Fracture characteristics of Carbon Fiber, Ceramic and non-Palladium endodontic post system at monotonously increasing loads. J. Oral. Rehab.2002; 29: 175-183.

46. Sakkal, S.:Carbon-fiber post removal technique.Compend. Contin. Educ. Dent., 20:86-87, 1998.

47. Taira, M.; Nomura, Y. and Wakasa K.: Studies on fracture toughness of dental ceramics.J. Oral. Rehabil., 17:551563,1990 .
48. Sidoli, G.E.; King, P.A. and Setchell, D.J.: An in vitro evaluation of a carbon fiber-based post and core system. J. Prosth. Dent., 78:5-9 1997

49. Scherrer, S.S.; De Rijk, W.G. and Belser, U.C.: Fracture resistance of human enamel and three all-ceramic crown systems on extracted teeth. Int. J. Prosthodont., 9:580585,1996 .

50. Turner, C.H.: Cement distribution during post cementation. J. Dent., 9:231-239, 1981.

51. Peters, M.C.; Poort, H.W.; Farah, J.W. and Craig, R.C.: Stress analysis of a tooth restored with a post and core. J. Dent. Res., 62:760-763, 1983.

52. Tjan, A.H.L.; Tjan, A.H. and Greive, J.H.: Effects of various cementation methods on the retention of prefabricated posts. J. Prosth. Dent., 58:309-313, 1987.

53. Deutsch, A.S.; Musikant, B.L.; Cavallari, J.; Tritchler, D. and Lepley, J.B.: Torque placed by dentist on prefabricated threaded post. J. Prosth. Dent., 53:323-325, 1985.

54. Morgano, S.M. and Milot, P.: Clinical success of metal posts and cores. J. Prosth. Dent., 70:11-16, 1993. 